\title{
"Kahlo em mim Eu e(m) Kahlo": A Performance do Meu Corpo Diferenciado
}

\author{
OLIVEIRA, Felipe Henrique Monteiro ${ }^{1}$
}

\section{Resumo}

Este artigo se pauta na pesquisa desenvolvida para a elaboração de dissertação de mestrado, no Programa de PósGraduação em Artes Cênicas da UFRN, sob orientação da Profa. Dra. Nara Salles e objetiva refletir sobre as questões relacionadas aos artistas com corpos diferenciados nos processos de criação cênica, sobretudo no teatro pós-dramático.

Palavras-chave:

Corpos Diferenciados; Teatro Pós-dramático; Frida Kahlo.

\section{Abstract:}

This article was in the research developed for the preparation of dissertation at Postgraduate Program in Performing Arts UFRN, under the guidance of phd Nara Salles and reflects on issues related to artists with different bodies in the process of creating scenic, especially in post-dramatic theater.

Keywords: Differentiated Bodies; Post-Dramatic Theatre, Frida Kahlo.
Mestrando do Programa de Pós-Graduação em Artes Cênicas da Universidade Federal do Rio Grande do Norte. Licenciado em Teatro pela Universidade Federal de Alagoas (2010). Membro do Núcleo Transdisciplinar de pesquisa em Artes Cênicas e Espetaculares. E-mail para contato: fhmoal@hotmail.com. 
Este artigo enfoca o processo de criação da performance "Kahlo em mim Eu e(m) Kahlo", que se configura como a parte prática da cena da dissertação desenvolvida no Programa de Pós-Graduação em Artes Cênicas da UFRN, sob orientação da Profa. Dra. Nara Salles, na qual discuto a criação de mecanismos socioeconômicos e culturais que permitem a instauração de estigmas nas pessoas com corpos diferenciados, expondo desta forma aos espectadores as questões políticas, sociais e culturais que acontecem na sociedade em que vivem, bem como proponho um diálogo entre meu corpo diferenciado e o corpo da artista plástica mexicana Frida Kahlo, também diferenciado.

O interesse pela artista mexicana vem do fato de que ao observar minuciosamente as suas obras, é possível afirmar que essas aludem a aspectos intrinsecamente ligados a sua intimidade, e isto fica mais evidente em seus autorretratos. Kahlo dizia em seus escritos que pintava a si mesma porque cotidianamente estava quase sempre sozinha, bem como era o assunto que mais conhecia.

$\mathrm{E}$ ao adentrar em seu universo pictórico, percebemos que sua arte traduz enfaticamente as circunstâncias e as experiências vividas que estão estreitamente relacionadas ao seu corpo diferenciado, como por exemplo: 1) aos seis anos de idade contraiu a poliomielite, a qual a enclausurou por nove meses em casa e a deixou com uma sequela em sua perna direita que ficou atrofiada; 2) acidente de ônibus, o qual escamoteou seu corpo - três fraturas na região lombar da coluna, fraturas na terceira e quarta vértebras, clavícula quebrada, luxação no cotovelo esquerdo, onze fraturas no pé esquerdo, pélvis quebrada em três lugares, peritonite aguda, cistite e ferimento profundo no abdômen, devido à barra de ferro que entrou no quadril esquerdo e saiu pela vagina, dilacerando o lábio esquerdo - e a fez com que ficasse um mês hospitalizada, permanecendo imobilizada em uma estrutura em formato de caixa, deitada de costas e com um colete de gesso colocado na região torácica; 3) três abortos sofridos no decorrer da vida, os quais a fez receber o seguinte prognostico dos médicos: devido as sequelas do acidente, ela dificilmente conseguiria manter qualquer bebê em seu útero, e essa é considerada a pior dor de toda sua vida; 4) uso contínuo de aparelhos e tratamentos ortopédicos - cadeira de rodas, sessões de tração, perna mecânica e coletes de aço, couro e gesso; 5) constantes crises depressivas, vício em drogas lícitas e ilícitas e alcoolismo; 6) episódios intensos de convalescença e solidão; 7) sucessivas cirurgias desnecessárias, como no caso em que devido às fortes dores que sentia na cabeça e na coluna em consequência do uso prolongado de 
coletes e outros aparelhos ortopédicos, e de um erro médico ocorrido durante uma punção lombar, algum tempo depois foi submetida a uma cirurgia na coluna, onde uma parte pedaço do osso pélvico foi incorporado a quatro vértebras da coluna fixado por uma haste de metal de quinze centímetros de comprimento, mas mesmo permanecendo acamada por cerca de oito meses, as dores na coluna continuaram, e isso fez com que os médicos observassem que a fusão espinhal não foi feita de forma correta, pois a haste de metal foi colocada em vértebras saudáveis; 8) amputação da perna direita na altura do joelho, a qual potencializou a diminuição de sua autoestima, ficando profundamente depressiva, e tendo ideias suicidas.

E ao pesquisar sistematicamente o universo biográficopictórico de Kahlo, pois já tinha o objetivo de concretizar o diálogo cênico entre nossos corpos diferenciados, surgiramme os seguintes questionamentos: Como expor meu corpo diferenciado em cena? Como dialogar meu corpo diferenciado com o corpo, também, diferenciado de Kahlo sem produzir clichês? Se não vou representar Kahlo, de qual maneira posso me apropriar de sua biografia e suas obras e imbricá-las no meu corpo em cena? Como posso penetrar em mim mesmo e descobrir os meus fantasmas psicológicos estigmatizantes que tanto me impedem de expor meu corpo diferenciado em cena? De qual forma minhas limitações psicofísicas são desbloqueadas a partir do contato comigo mesmo diante do público em cena enquanto performer?

Diante dos questionamentos, optei criar uma performance. No contexto da arte, a performance, sendo essencialmente uma arte de fronteira que penetra e se influencia nos díspares territórios artísticos, no seu contínuo movimento de ruptura com a arte estabelecida, adentra por caminhos e situações antes não valorizadas como arte, propondo esmiuçar as fronteiras tênues que separam vida e arte. Sendo assim, a performance não enseja a representação do real, mas a reelaboração do real, na qual a obra de arte tem vida própria e não se limita a representar o objeto mimeticamente, como ocorre no teatro dramático.

Em concomitância, RoseLee Goldberg (2006) aponta que na performance, diferente do que acontece no teatro tradicional de cunho dramático, o performer não se transforma em um personagem, pois enseja ser ele mesmo em cena e sua cena raramente segue um enredo ou uma narrativa psicológica. $\mathrm{O}$ performer trabalha em cima de suas habilidades, pois a medida que não tem, como no teatro dramático, a intenção de representar mimeticamente um personagem para mostrar, tem que 
desenvolver e mostrar suas habilidades pessoais, sua idiossincrasia, pois o que interessa é sua marca pessoal ou grupal, caso a performance seja em grupo. O performer tem por objetivo a definição de um estilo artístico poroso, de uma linguagem própria que seja expressa pelo seu corpo em ação. Pois,

O performer não interpreta um papel (recuperando e recobrindoo). O que ele faz é remover resistências e bloqueios que o impedem de atuar de uma maneira inteira, seguindo completamente seus impulsos interiores em resposta às ações de um papel. $\mathrm{Na}$ performance, o papel é o papel, e o performer é o performer. Além disso, o performer é um especialista em cantar, dançar, falar, em movimentação corporal; ele está em contato com os seus próprios centros; ele é capaz de se relacionar livremente com os outros. (SCHECHNER, 2009, p. 335)

No âmbito da performance não somente o íntimo do performer é exposto, mas também o público. Por esta razão, o performer é o autor da sua performance, e frequentemente expõe aos espectadores as questões políticas, sociais e culturais que acontecem na sociedade em que vivem.

Neste contexto, assumi a função de performer e, além de abordar a influência da instauração do estigma dos corpos diferenciados no acontecimento cênico e seus desdobramentos nas relações interpessoais na sociedade contemporânea, institui em minha prática cênica a apropriação do universo biográfico-pictórico da artista Kahlo. Entendendo por apropriação, uma palavra derivada do verbo apropriar, e que uma de suas significações é tomar para si, assim na performance degluto antropofagicamente Kahlo, e ao descobrir o martírio de seu corpo diferenciado, a regurgito artisticamente e passo a utilizar os mais marcantes episódios de sua biografia pessoal e artística como aportes para o meu processo criativo, no qual proponho um diálogo irredutível entre as dores do corpo diferenciado da artista plástica mexicana em relação ao meu próprio corpo.

No que concerne ainda a conceituação de performance Jacó Guinsburg (apud COHEN, 2009) promulga-a como sendo a uma expressão cênica caracterizada por uma tríade essencial básica, na qual seus componentes são interseccionados e se intercomunicam: atuante - texto - público. $O$ atuante não precisa ser um ser humano, no caso o ator, ou o performer, pode ser um animal, um boneco, e até mesmo um objeto. Já o texto deve ser entendido como conjunto de signos que podem ser simbólicos, icônicos e indiciais. Ao público é ideal se considerar duas formas cênicas básicas: a forma estética, na qual implica o espectador ser apenas observador no processo de 
fruição, e a forma ritual, em que o público assume uma posição de participante.

No teatro dramático, o atuante, apesar de interpretar com base em sua subjetividade, se torna um mero condutor/enunciador das ações miméticas presentes nos textos produzidos a priori, das intenções do dramaturgo, das diretrizes apontadas pelo diretor para conduzir sua introspecção psicológica e gestual da personagem e da condução do processo de fruição do espectador. $\mathrm{O}$ atuante passa a portar em seu ofício artístico uma duplicidade, ou seja, tanto quer viver de modo simulado quanto quer mostrar sua capacidade de representação, quer ser ele mesmo e uma personagem, um ser fictício encarnado em um ser humano.

Jerzy Grotowski examina o trabalho do ator no teatro dramático, o qual denomina como teatro rico, com a crítica a seguir:

\footnotetext{
O ator é um homem que trabalha em público com o seu corpo, oferecendo-o publicamente. Se este corpo se limita a demonstrar o que é - algo qual qualquer pessoa comum pode fazer - não constitui um instrumento obediente capaz de criar um ato espiritual. Se é explorado por dinheiro e para ganhar os favores da platéia, a arte de representar está à beira da prostituição. [...] O que impressiona quando se observa a atuação de um ator, tal como é praticada hoje em dia, é a mesquinharia de seu trabalho: a barganha feita por um corpo explorado pelos seus protetores - diretor, produtor - criando em retribuição uma atmosfera de intriga e revolta. (GROTOWSKI, 1992, p. 29)
}

Nas manifestações cênicas pós-dramáticas, as quais a performance está inserida, o atuante não tendo mais como procedimento usual estruturar sua atuação na materialização de significados preestabelecidos, como no caso da ilustração de situações e circunstâncias indicadas no texto dramático, tem agora uma gama de possibilidades que abrem espaço para evidenciar em cena sua corporeidade e suas qualidades expressivas, a rearticulação de códigos e convenções culturais e o desenvolvimento de sua idiossincrasia.

Em "Kahlo em mim Eu e(m) Kahlo" tanto não represento mimeticamente a artista mexicana quanto combato os mecanismos ilusionistas e artificiais que foram tão difundidos pelo teatro dramático, pois assumi, através da fusão antropofágica com Kahlo, a total responsabilidade de, a partir do conhecimento do meu corpo, mostrar meu próprio corpo diferenciado ao público em cena, através de um ato que não permite diferenciar o que é arte e o que é vida, visto que me transformo simultaneamente em sujeito, objeto e trajeto de arte. 
Quanto ao texto, até o surgimento das diferenciadas manifestações cênicas nas últimas décadas do século XX, é possível percebê-lo em uma espécie de complementaridade/ simbiose com o drama. É por este motivo que o texto dramático, de modo genérico, passou a ser considerado como sendo uma noção normativa idêntica a própria arte teatral. Ao teatro caberia simplesmente reproduzir as categorias de imitação e ações miméticas e estar a serviço de ilustrar a realidade fictícia arrematada pelo texto dramático. Sobre os efeitos do paradigma dramático no teatro, é necessário atentar que:

\footnotetext{
Essa idéia da supremacia da palavra no teatro está tão enraizada em nós, e o teatro nos aparece de tal modo como o simples reflexo material do texto, que tudo o que no teatro ultrapassa o texto, que não está contido em seus limites e estritamente condicionado por ele parece-nos fazer parte do domínio da encenação considerada como alguma coisa inferior em relação ao texto. [...] Considerando-se essa sujeição teatro à palavra, é possível perguntar se o teatro por acaso não possuiria sua linguagem própria, se seria absolutamente quimérico considerá-lo como uma arte independente e autônoma, assim como a música, a pintura, a dança, etc., etc. (ARTAUD, 2006, p. $75-76$ )
}

Essa perspectiva em considerar o teatro como literário e narrativo delimita no público, que estava acostumado a observar o discurso dramático em cena, o estranhamento diante do teatro pós-dramático, pois se exige do espectador a redefinição de sua percepção ao discurso polifônico do novo modelo de teatro pós-dramático.

O teatro pós-dramático ao se livrar da trindade do texto dramático (drama, ação e imitação) abre espaços para dramaturgias multiformes desprovidas intencionalmente de significados referenciais, no sentido estrito de representações miméticas, que conclamam a instituição de textos polifônicos construídos pela e para a cena, seus elementos constituintes e por seus artistas. O teatro pós-dramático, e aqui se insere a performance, ao desmantelar as dinâmicas dramáticas, abdica da categoria de ação em favor do estado ou situação de dinâmica cênica. Deste modo, substitui a ação dramática aristotélica pela cerimônia, perfazendo na dimensão que adere diversos procedimentos teatrais conduzidos sem referencial no processo criativo.

O texto submetido à dinâmica ambígua, plurivalente e simultânea da cena possibilita a supressão da síntese em prol de uma nova dramaturgia que cultiva estruturas construídas na processualidade do acontecimento artístico do que 
a priori, dando ao espectador a oportunidade de vivenciar uma experiência real que prioriza uma percepção aberta e fragmentada no lugar de uma percepção padronizada. É por isso que se pode estabelecer a predominância do texto da performance na cena do teatro pós-dramático, pois o mesmo "se torna mais presença do que representação, mais experiência partilhada do que comunicada, mais processo do que resultado, mais manifestação do que significação, mais energia do que informação." (Idem, p. 143).

Em "Kahlo em mim Eu e(m) Kahlo" optei por criar uma dramaturgia bifurcada em dois vieses: a visual e a narração de experiências pessoais. O primeiro é constituído por novos modos de ver o performer em cena através de lanternas que designam as cores utilizadas pela artista mexicana, projeção de fotografias de Kahlo, com amigos e parentes e suas obras, figurinos e utilização de aroma de lavanda a fim de provocar sinestesias nos espectadores; o segundo se elabora na narração de minhas experiências pessoais (nascimento, corpo diferenciado, minha doença, hospital Sarah de Salvador, exame de DNA, Amiotrofia Espinhal Progressiva, infância e internações, escola, preconceito de algumas freiras e professores, adolescência, amigas na escola, faculdade, arte e performance).

A dramaturgia de "Kahlo em mim Eu e(m) Kahlo" se pauta no entendimento de Eugenio Barba (apud SALLES, 2004) que afirma que antes de se fazer referência a um texto escrito ou falado em cena, o texto exprime 'tecendo junto', assim podese entender que não existe manifestação cênica sem texto.

Sobre a escolha da iluminação, esclareço que no início da performance, quando estou contando fatos da minha vida, são entregues individualmente trinta lanternas para trintas espectadores por um assistente de cena. Essas têm como efeito delimitar a escolha da visão do espectador em ver, na medida em que se defronta, determinada parte do meu corpo diferenciado no espaço cênico partilhado, além de projetarem as cores usadas por Kahlo em seus escritos, esboços e pinturas, produzindo assim uma atmosfera onírica. Nesse ponto, a iluminação de "Kahlo em mim Eu e(m) Kahlo" dialoga com as ideias da proposição cênica artaudiana:

Entrando em jogo a ação particular da luz sobre o espírito, devemse buscar efeitos de vibração luminosa, novos modos de difundir a iluminação em ondas, ou por camadas, ou como uma fuzilaria de flechas incendiárias. [...] A fim de produzir qualidades de tons particulares, deve-se reintroduzir na luz um elemento de sutileza, densidade, opacidade, com o objetivo de produzir calor, frio, raiva, medo, etc. (ARTAUD, 2006, p. 109) 


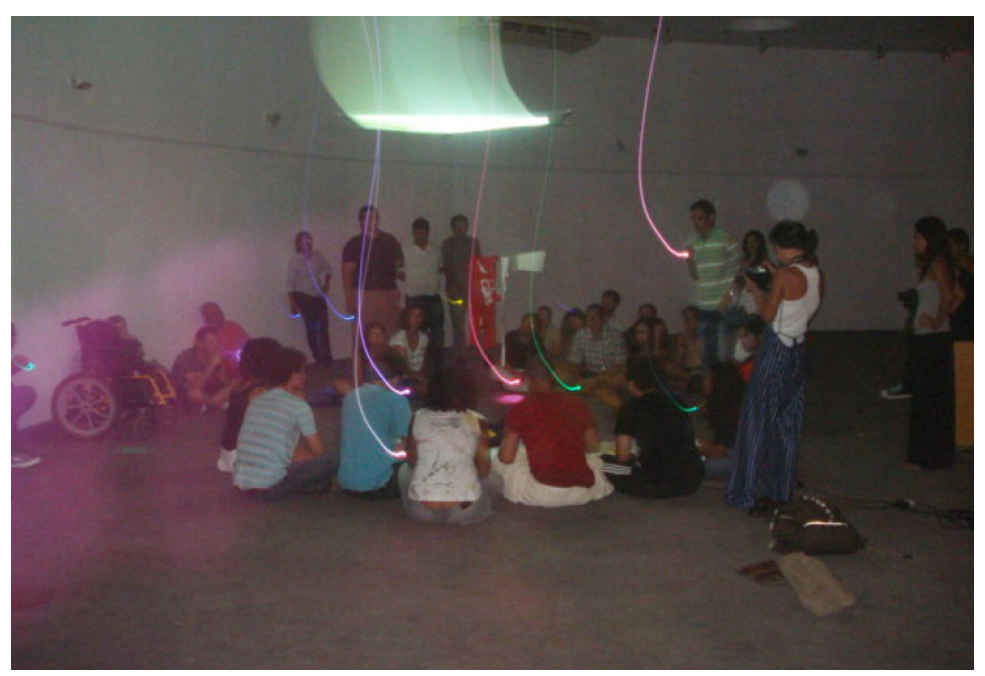

Reportando-se aos figurinos, concebi-os com a colaboração da designer de moda e figurinista Carolina Moreira Salles. Desde o começo de nossas investigações, optamos por não criá-los sob o aspecto mimético para ilustrar os caracteres de personagens e servir de simples vestimenta para o atuante. Escolhemos fazer alusão às obras e aos episódios que marcaram decisivamente o corpo diferenciado de Kahlo. Os figurinos fazem jus ao pensamento artaudiano, pois remetem a atmosferas oníricas e valorizam o uso de materiais não cotidianos, cores fortes, cortes assimétricos e contraste entre os diferentes tipos de tecidos, como por exemplo: malhas de algodão amarelas, pretas, brancas e vermelhas; tintas vermelha, amarela e verde em alto relevo; glitter dourado; fitilhos verdes; sapato de couro amarelo com cadarço vermelho.

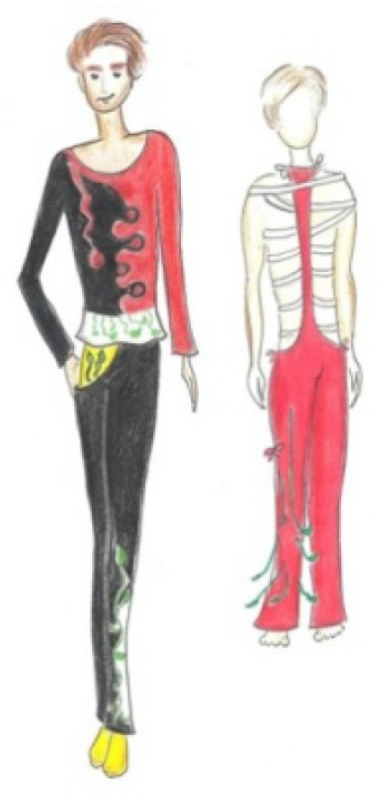

Figura 1.

Iluminação da performance "Kahlo em mim Eu e(m) Kahlo".

Figura 2.

Figurinos da performance "Kahlo em mim Eu e(m) Kahlo". Croquis: Carolina Moreira Salles. 
O uso do aroma de lavanda borrifado no espaço cênico de "Kahlo em mim Eu e(m) Kahlo" se estabelece como uma forma de favorecer aos espectadores a possibilidade de experimentarem o trabalho artístico por meio de sinestesias, e não somente através de uma leitura visual, tátil e auditiva. Por sinestesia se compreende a ideia de perceber o mundo por meio da relação subjetiva provocada espontaneamente pelos sentidos, por exemplo, no caso da presente performance o aroma pode evocar nos espectadores memórias relacionadas à imagens, paladares, sensações e/ou sons, fazendo com que o indivíduo seja atravessado por emoções provenientes da produções de sentidos difundidos em cena. A escolha do aroma de lavanda está relacionada ao fato de que, geralmente, se utiliza em recém-nascidos e crianças este odor, logo tive a intenção de reportar a impossibilidade de Kahlo ter filhos.

Quanto à escolha pela narração de episódios da minha vida como procedimento dramatúrgico, procurei dialogar com as cartas e outros escritos da artista mexicana de forma que pudesse renunciar a construção de personagem e a interpretação de uma fábula linear, pois quis trabalhar em cena nossos corpos diferenciados também a partir da criação do meu monólogo narrativo autobiográfico, proporcionando uma mescla de referencialidades.

No tocante ao público, no teatro dramático o espectador é agenciado e manipulado a assumir uma posição passiva durante o processo de fruição da obra de arte apresentada em cena, visto que sua presença é negligenciada e esquecida durante todo o evento teatral, só sendo lembrado em momentos de erros do elenco e no final do espetáculo, quando é coagido educadamente a aplaudir, pois somente nesse instante seu processo ilusório de identificação com as personagens e situações pertencentes à peça é quebrado.

A partir da quebra com os princípios da ficção e da mimese, e do enquadramento do teatro pós-dramático no paradigma da cena pós-dramática como work in progress, ou seja, trabalhos artísticos que não ensejam se tornar simples produtos de processos criativos, mas que pretendem se constituir na processualidade - "Kahlo em mim Eu e(m) Kahlo" se enquadra na cena como work in progress - o espectador é compelido a perceber a obra de arte em seu próprio processo constituinte, o qual culmina na necessidade desse sujeito participar ativamente do ato artístico e permitir que sua percepção se torne aberta, sobrecarregada e não acabada. Isto porque é oferecido ao espectador desta cena o reconhecimento de sua presença, já que os artistas propõem diferentes maneiras de experimentar, estimular, provocar, convidar, desafiar e vivenciar a experiência artística, e não mais o con- 
sidera como sendo apenas um receptáculo que é silenciado passivamente durante o processo de fruição.

Em relação à participação do espectador durante o acontecimento artístico, há a existência de dois modelos: o modelo estético e o modelo mítico. O que possibilita a diferenciação do estético do mítico é o fato de que no primeiro existe uma percepção mais racional em relação ao objeto, ou seja, o espectador não penetra efetivamente no ato artístico, e se torna apenas um observador durante o processo de fruição com a obra de arte apresentada. Na relação mítica o distanciamento racional não fica demasiadamente elucidado, pois o espectador penetra na obra e passa a ser considerado como participante.

Em "Kahlo em mim Eu e(m) Kahlo" os dois modelos estão interseccionados, visto que mesmo quando estabeleço algumas ações que possibilitam a participação ativa de alguns espectadores, os outros ficam apenas observando, como por exemplo quando solicito que me tirem da cadeira de rodas e me coloquem deitado no colchonete colocado no centro do espaço, quando peço que retirem meu figurino e o solicito a cada espectador que escreva individualmente, uma palavra ou uma frase sobre o que pensou e sentiu no momento em que me ajudou e viu meu corpo diferenciado nu, e em seguida fotografe-a.

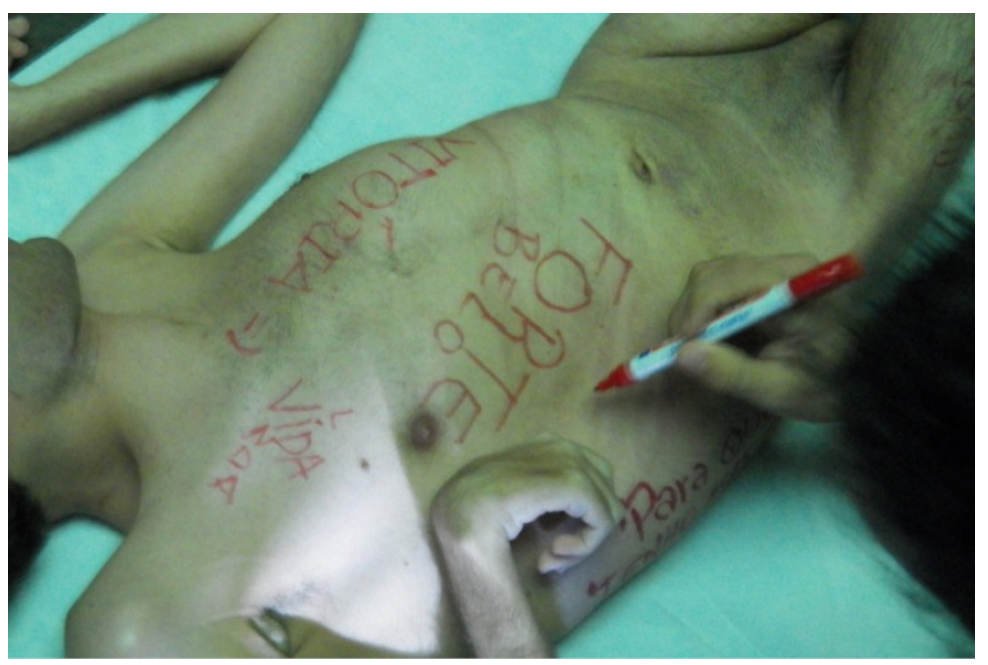

Essas palavras e frases advêm da constatação de que ao expor a fragilidade e a vulnerabilidade do meu corpo diferenciado nu em cena acabo provocando e subvertendo as convenções socioculturais e educativas que tanto domesticam as manifestações corporais com as quais os espectadores estão submetidos e acostumados na sociedade contemporânea. E a exposição da nudez em cena passa a adquirir um caráter político, pois o corpo do performer na expressão artística, passa
Figura 3.

Palavras e frases escritas em meu corpo diferenciado pelos espectadores na performance "Kahlo em mim Eu e(m) Kahlo". 
a ser o espetáculo em si, e propõe "a dialética entre os padrões da conduta humana e as estruturas nas quais se apóia entram em crise" (GLUSBERG, 2003, p. 90).

A nudez do meu corpo diferenciado em cena foi particularmente um processo complexo, pois tive que fazer uma ação de autopenetração, a fim de sacrificar os estigmas mais recônditos da parte mais íntima de mim mesmo, e desta maneira pude subverter, transgredir e eliminar os estigmas que foram inseridos durante toda minha vida. Ou seja, tive que ser plenamente sincero comigo mesmo e com os espectadores, posto que não me escondo por trás de um personagem ou finjo artisticamente algo, mas ofereço humilde e corajosamente meu corpo diferenciado ao público em um ato real de provocação. Assim, o processo que possibilitou a minha nudez em cena se assemelha com o ideal do ator santo pensado por Grotowski:

[...] Se o ator, estabelecendo para si próprio um desafio, desafia publicamente os outros, e, através da profanação do sacrilégio ultrajante, se revela, tirando sua máscara do cotidiano, torna possível ao espectador empreender um processo idêntico de autopenetração. Se não exibe seu corpo, mas anula-o, queima-o, liberta-o de toda resistência a qualquer impulso psíquico, então, ele não vende mais o seu corpo, mas o oferece em sacrifício. (GROTOWSKI, 1992, p. 29)

A participação ativa dos espectadores em "Kahlo em mim $\mathrm{Eu}$ e(m) Kahlo" permite o estabelecimento da confluência entre arte e vida, produzindo um contexto ritualístico, no qual promove a possibilidade do espectador não se tornar um simples observador do ato artístico, pois assume uma posição de cúmplice, testemunha, coautor. Mas vale salientar que a interação entre espectador e performer permite a reorganização da composição cênica e do espaço, pois na medida em que proponho um alto grau de liberdade desse sujeito participar da performance, uma vez que diminuo propositalmente o controle sobre a cena, mais o partícipe terá também a função de ser compositor do ato artístico, assim

\footnotetext{
A tarefa do espectador deixa de ser a reconstrução mental, a recriação e a paciente reprodução da imagem fixada; ele deve agora mobilizar sua própria capacidade de reação e vivência a fim de realizar a participação no processo que lhe é oferecida. (LEHMANN, 2007, p. 224)
}

Esse acontecimento ritualístico efetuado no real, no aqui e agora, que tem como características potencializar a experiência vivida, articular o passado com o que está acontecendo no presente da cena, intensificar a abertura da percepção, delinear a experiência partilhada tornando possível a construção de novos significados e suscitar experiências passadas 
de forma que os sujeitos revelem suas incompletudes e as suas necessidades de se completarem como seres humanos a partir do contato com o outro.

A participação do público em "Kahlo em mim Eu e(m) Kahlo é propiciada, sobretudo, pela forma de lidar com espaço, posto que desejei torná-lo partilhado. Esse tipo de espaço oferece aos espectadores a opção de ir e vir no momento em que desejarem, pois a porta de entrada está aberta durante toda a performance.

A escolha pelo compartilhamento espacial contribui para a instauração dos seguintes fatores em "Kahlo em mim Eu e(m) Kahlo: permite que o espectador se torne um coatuante, junto aos outros, da coletividade performática; reconhece o valor individual de cada espectador como agente compositor da cena; permite o espectador estar consciente de seu papel de testemunha da performance; relação corpórea e espacial provocada pela proximidade dos corpos favorece o contato imediato entre performer e público para a qual cada sujeito, em sua própria presença, incita intencionalmente uma comunicação interpessoal.

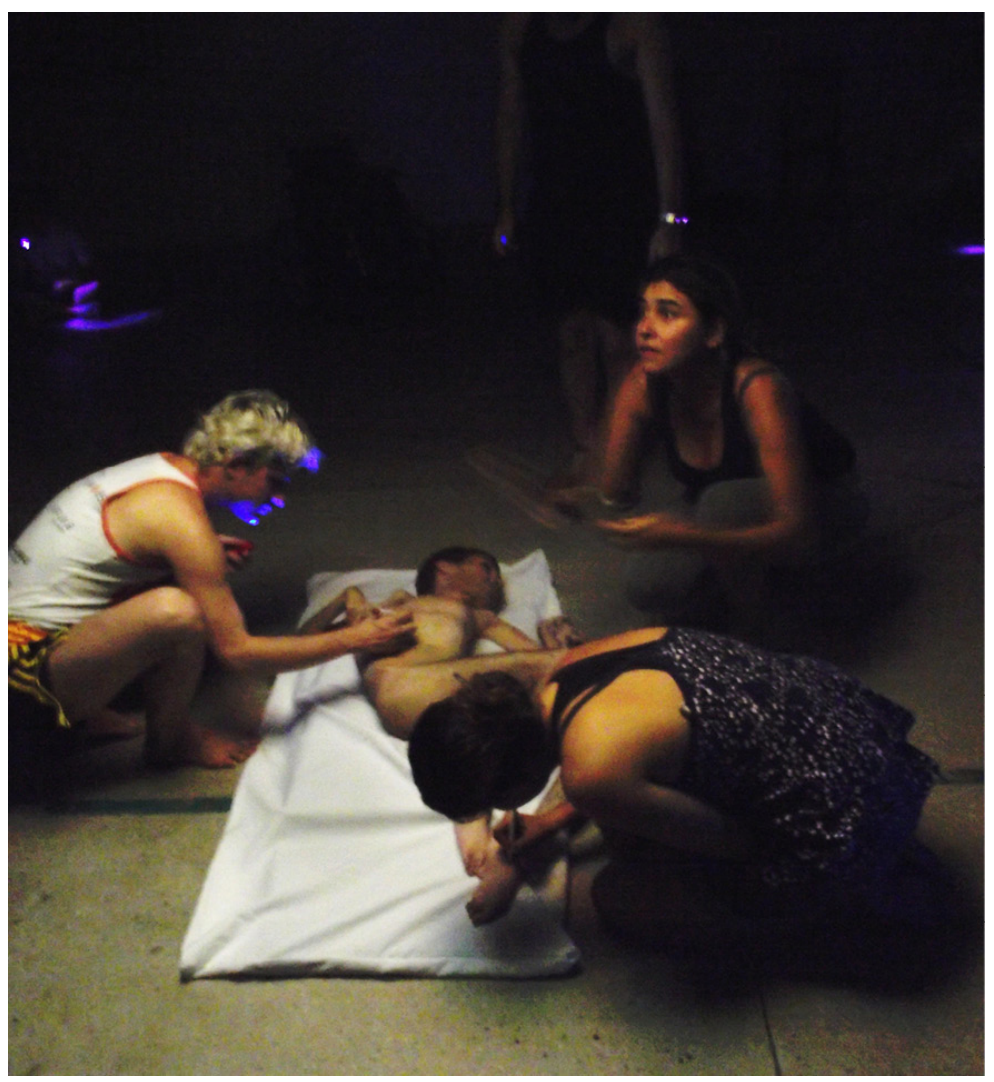

Entendendo que o êxito da performance reside em sua capacidade comunicativa, a qual é gerada a partir da experiência real dos participantes no aqui e agora, em minhas ações
Figura 4.

Espectadores na performance "Kahlo em mim Eu e(m) Kahlo". 
são diretamente dependentes da disponibilidade dos espectadores em me ajudar em cena quando são solicitados, culminando deste modo em um jogo em que os sujeitos podem fazer o que quiser com meu corpo diferenciado no decorrer do acontecimento cênico, logo a percepção acaba se convertendo em uma experiência de responsabilidade.

Sendo assim, na performance "Kahlo em mim Eu e(m) Kahlo convido os espectadores a despertar suas emoções sobre o fato de manusear meu corpo diferenciado, autotransformado em arte, e trago à tona na cena do processo real os momentos que modificam perenemente o modo crítico de pensar e lidar com e sobre a marginalização dos artistas com corpos diferenciados, a transgressão dos estigmas impostos a esses indivíduos tanto socialmente quanto artisticamente e a reflexão de que qualquer artista com corpo diferenciado, cujo é cotidianamente estigmatizado, pode e é capaz de fazer arte, pois nas artes cênicas, especialmente no teatro pós-dramático e suas vertentes, nas quais a performance está inserida, de acordo com Lehmann (2007), os artistas com corpos diferenciados que até então eram, e infelizmente ainda são, tanto na arte quanto na sociedade, marginalizados e estigmatizados pelo simples fato de não atenderem às expectativas normativas propagadas e julgadas constantemente como ideais para todos os seres humanos, podem ser incluídos efetivamente no campo das artes, pois suas aparentes fragilidades, incapacidades e vulnerabilidades são aceitas e reconhecidas como potenciais criativos para os processos de criação e configuração cênica.

Portanto pude compreender e comprovar a partir da pesquisa de mestrado que as artes cênicas na contemporaneidade não impõem juízos de valor sobre quais são os corpos que devem ou não participar e estar presente em cena, pois agora se objetiva discutir, reconhecer e se apropriar da diversidade e da alteridade dos artistas, dentre eles os com corpos diferenciados. 


\section{REFERÊNCIAS BIBLIOGRÁFICAS:}

ARTAUD, Antonin. O teatro e seu duplo. São Paulo: Martins Fontes, 2006.

COHEN, Renato. Performance como Linguagem. São Paulo: Perspectiva, 2009.

Work in progress na cena contemporânea: criação, encenação e recepção. São Paulo: Perspectiva, 2006.

GOLDBERG, RoseLee. A arte da performance: do futurismo ao presente. São Paulo: Martins Fontes, 2006.

GLUSBERG, Jorge. A Arte da Performance. São Paulo: Perspectiva, 2003.

GROTOWSKI, Jerzy. Em Busca de um Teatro Pobre. São Paulo: Civilização Brasileira, 1992.

LEHMANN, Hans-Thies. Teatro pós-dramático. São Paulo: Cosac Naify, 2007.

LIGIÉRO, Zeca (Orgs). Performance e Antropologia de Richard Schechner. Rio de Janeiro: Mauad X, 2012.

SALLES, Nara. Sentidos: Processos Criativos a Partir da Poética de Antonin Artaud. Tese de Doutorado PPGAC/UFBA. 2004.

SCHECHNER, Richard. Performer. Revista Sala Preta. São Paulo: n. 9, 2009, p. $333-365$. 